UCL ENVIRONMENTAL CHANGE

\title{
RESEARCH CENTRE
}
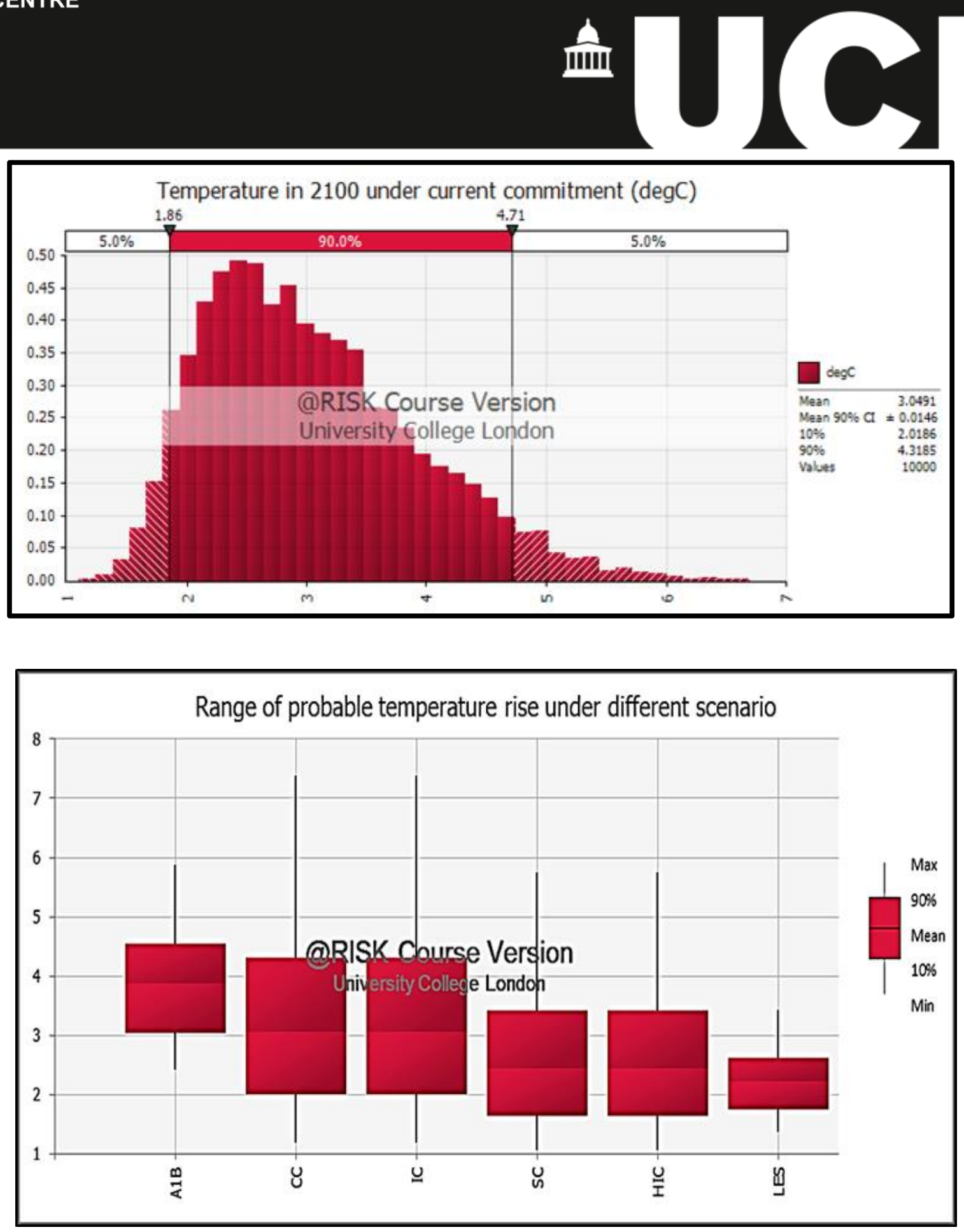

Ratcheting up ambition on climate policy

ECRC Research Report Number 182

Bishal Bharadwaj and Chris Brierley 


\title{
Ratcheting up ambition in climate policy
}

\author{
Bishal Bharadwaj and Chris Brierley
}

ECRC Research Report Number 182

Environmental Change Research Centre

University College London

Pearson Building, Gower St.

London, WC1E 6BT 


\section{Contents}

1. 2. 3. 3.1 . 3.2. 3.3. 3.4 3.5 . 4. 5. 6. 7 8. … PAGE09, an Integrated Assessment Model (IAM)

\section{4} Future Emission Scenarios under NDCs 5 ..Current commitment (CC) 6 Increased Commitment (IC) Stringent Commitment (SC) 6 Highly Increased Commitment (HIC) 7 ..Other scenarios Climate Change Outcomes .8 Costs of NDC-based scenarios . .9 Social Cost of Carbon 11 Discussion and Conclusions 12 References Error! Bookmark not defined. 


\section{Summary}

The historic Paris Agreement aims to constrain the peak increase in global mean temperature to $1.5^{\circ} \mathrm{C}$, or at least well below $2{ }^{\circ} \mathrm{C}$. Every country has committed to device their own "nationally determined contributions" towards this target. These contributions are only proscribed for the coming 10-15 years with a regular reassessment of them against the global target. Here we use a global climate-economy model to explore consequences of differing levels of ambition during these reanalysis. We find that without substantially increased ambition the probability of avoiding $2{ }^{\circ} \mathrm{C}$ of warming is marginal. We present several plausible future trajectories that significantly increase the probability of avoiding 2 ${ }^{\circ} \mathrm{C}$, but are unable to keep global temperatures below $1.5^{\circ} \mathrm{C}$. We advocate countries engage in the reassessment process soon and with high ambitions as catastrophic climate change can effectively be ruled out by such actions.

\section{Human Induced Climate change and COP21}

COP21 has now negotiated a global commitment to limit temperature rise well below $2{ }^{\circ} \mathrm{C}$. The scientific community suggest a target of $2^{\circ} \mathrm{C}$ is insufficient but encouraging (Schleussner, et al., 2016), but recognise that the negotiations necessarily incorporate political factors rather than being solely science-based (Puiu, 2015). The Paris Agreement was built upon a collection of Nationally Determined Commitments (NDCs) - each country stating how and how much they will reduce their greenhouse gas emissions. These commitments are specified up to at most 2030. Recent studies indicate these are insufficient to hold warming below $2{ }^{\circ} \mathrm{C}$ (Rogelj, et al., 2016). The resultant peak temperature depends on the ambitions shown by what follows the current commitments. Designing climate change policy is a complex process; influenced by intergenerational equity, sustainable development, localized investment for commons benefits, allocative choices between adaptation and prevention amongst others. Integrated Assessment Models (IAM) are often used to track the outcomes of climate policies through the input of plausible scenarios.

\section{PAGE09, an Integrated Assessment Model (IAM)}

This research uses the "Policy Analysis of Greenhouse Effect" integrated assessment model (PAGE09; Hope, 2011). A previous generation of the model provided the quantitative projections for the influential Stern Review (Stern, 2007). It is one of a handful of models used to calculate the social costs of carbon implemented by institutions such as the US EPA and the World Bank. Its main advantage over other similar models is its inherently probabilistic approach. It uses a Monte Carlo approach to sample uncertain parameters (such as the climate sensitivity and discount rate) and incorporates the existence of low probability, but high impact climate discontinuities. 
PAGE09 incorporates climate forcings from aerosols and greenhouses gases (specifically $\mathrm{CO} 2, \mathrm{CH} 4, \mathrm{~N} 2 \mathrm{O}$ and SF6) at unevenly-spaced intervals until 2200. It samples a range of parameters consistent with the Intergovernmental Panel on Climate Change (IPCC) Assessment Report 4 (Hope, 2011). PAGE09 considers impacts in multiple categories, (a) economic including factors such as agriculture, (b) non-economic such as health risks and (c) discontinuities, which arise from crossing a climate threshold like Greenland melting and (d) sea level rise (Hope, 2013). Costs relating to abatement (i.e. mitigation) and adaptation are estimated using an equity weighting and an elasticity of utility above one (meaning a dollar has more worth to those with few of them). Discount rates are based on the Ramsay rule (Hope, 2006; Tol, 2015). A Monte Carlo approach gives probabilistic outcomes, yet the (slim) possibility of catastrophic damages invariably skews the distribution. The model uses eight distinct economic blocs: the European Union (EU) including Britain; the United States of America (US); Other OECD countries (OT); Eastern Europe including the former Soviet Union (EE); China and central Asia (CA); India including South East Asia (IA); Africa and Middle East (AF); and Latin America (LA).

\section{Future Emission Scenarios under NDCs}

Previous assessments suggest any $2^{\circ} \mathrm{C}$ pathway involves peaking the emissions as soon as possible (AVOID2, 2009) and have net-zero emissions before 2100 (Fuss, et al., 2014; Schleussner, et al., 2016). Emission peak year and zero emission year are important milestones in these pathways, both of which depends on annual emission reduction rate. The post-2030 scenarios presented here are developed to hasten the emission peak year and increase the reduction rate. Climate justice remains as crux of these scenarios that recognize negotiation is give and take process. Developed countries will pressure developing countries to increase their ambition, yet the chances that developing countries will accept depends on the progress of the developed regions.

There are several complications when developing NDC-based emission pathways arising from (a) the aggregated economic blocs, (b) the NDCs often only lasting until 2030, and (c) the fact that some NDCs lack an explicit target either the emissions peak year or emission reduction rate. We set out to develop scenarios that are simultaneously ambitions, but also plausible. A country's annual emission reduction rate is calculated from its chosen reduction target and baseline in its NDC, or if necessary from its Kyoto Protocol pledge. Given heavy dependence on technological innovation, we assume that increasing marginal abatement costs will be countered by technology cost reductions, which might not be true for all regions and depends on the nature of production (Brechet \& Jouvet, 2008). This assumption allows us to expand emission scenario across the majority of the OECD. For regions with high population growth, substantial poverty and a developing economy like India, emission pathway still has to peak and then decline. Furthermore, uncertainty increases with unclear climate policies (Ghambhir, et al., 2014) and conditional targets (Rogelj, et al., 2016). Delayed action has greater implications than mitigating technology (Rogeij, et al., 2014). By considering what could follow the NDCs after expire in 2030, four plausible scenarios are developed and contained in the carbon budget space delimited 
within the A1B pathway (as a baseline) and LES (AVOID, 2016; which contains unlikely, stringent emission reductions to achieve a $1.5^{\circ} \mathrm{C}$ target). We assume that all other greenhouse gases follow the same trajectory as carbon dioxide.

Emission scenarios until 2030 use selected data from published articles, inventories and policy documents (Green \& Stern, 2015; Li \& Qi, 2011; EEA, 2010; CAT, 2014; UNFCCC, 2014 (b); UNFCCC, 2015; Rogelj, et al., 2016). We assume that the NDCs will have an effective implementation and a progressive follow-up after 2030 (Jacquet \& Jamieson, 2016). Regional emissions are used where available, such as for the EU. For regions with wide disparities in emission goals like Latin America, sub-regional or country-wide emissions are expanded and then aggregated to produce regional emission pathways. We neglect countries with a very minor contribution to the bloc (such as Nepal for the India \& South East Asia bloc). As the NDCs are now in effect, all scenarios follow the same trajectory initially. After 2030 , they diverge as varying progressive but plausible commitments are added. Four different emission scenarios are developed and are summarized in Table 1 and Figure 1.

\subsection{Current commitment (CC)}

The scenario is based on the principle that countries will continue reducing their emissions. They will be sufficiently committed to maintain a similar rate of emission reduction, despite the increasing marginal costs of mitigation. For nations such as China that have a stated emissions peak, we use the slowing of emissions growth before the peak as an emissions reduction rate for afterwards. For regions where the NDC commits to neither a peak year nor an emissions reduction rate, we choose default emission pathways that follow the A1B scenario (our baseline case for the NDC-based commitments). The highest current annual emissions reduction rate is 2\%-per-year for both the EU and US, whereas both India and South East Asia (IA) and Africa \& Middle East (AF) increase their emissions by $176 \%$ by the end of century (as they follow the A1B).

\subsection{Increased Commitment (IC)}

This scenario considers that in light of emerging evidence (Rogelj, et al., 2016;

Schleussner, et al., 2016), nations will increase their climate commitments. It has been suggested that countries like India, South Africa and the Gulf states may peak their emission before 2040 (Ekholm \& Lindroos, 2015). In response, developed countries will increase their emission reduction rate (MacKay, et al., 2015). This increasing commitment sees two additional blocs (IA and AF) peak their emission (in 2040, followed by a 1\%-peryear reduction rate until 2050, 2\%-per-year until 2075 and 3\%-per-year thereafter). Developed countries increase their emissions reduction rate by a further $1 \%$-per-year. This results in 6 of the 8 regions achieving zero emissions by 2100 (Figure 1B).

\subsection{Stringent Commitment (SC)}

This scenario considers that policy is determined in light of evidence that early action is essential (UNFCCC, 2015b; Peters, 2016). It assumes that all nations will peak their emissions by 2030 or earlier. However, this urgency is not transferred to tackling 
emissions after this peaking - the emissions reduction remains the same in the increased commitment scenario above. Both India and South East Asia (IA) and Africa \& Middle East (AF) implement emissions reduction rates of 1\%-per-year, $2 \%$-per-year and $3 \%$-per-year after 2040, 2050 and 2075 respectively. In this scenario, all regions achieve net-zero emissions by 2100 .

\subsection{Highly Increased Commitment (HIC)}

In this scenario, we suppose that all regions match the ambition of a global peak in emissions by 2030 , followed by intense decarbonisation. As such all emissions reduction rates are increased by $2 \%$-per-year above those implied by the current commitments. This results in all regions achieving net-zero emissions by 2100 , whilst the EU and the USA will achieve it in 2050 . The resulting emission scenario is roughly comparable to the RCP2.6 scenario.

\subsection{Other scenarios}

To illustrate the implications of the above scenarios, we also show the results of the following scenarios:

- A1B - a scenario which represents high economic growth but balanced technology diffusion (IPCC, 2014)

- LES - a scenario devised by the AVOID project that has a 50\% probability of achieving 2 ${ }^{\circ} \mathrm{C}$ (Warren, et al., 2013)

Table 1 Description of Scenarios

\begin{tabular}{|l|l|l|l|}
\hline Scenario & Concept & Description & Projection \\
\hline $\begin{array}{l}\text { Current } \\
\text { (CC) }\end{array}$ & $\begin{array}{l}\text { Maintain and } \\
\text { implement } \\
\text { current } \\
\text { reduction } \\
\text { rates }\end{array}$ & $\begin{array}{l}\text { Extension of NDCs; } \\
\text { defaults to A1B scenario } \\
\text { if no reductions } \\
\text { promised }\end{array}$ & $\begin{array}{l}\text { Developing world } \\
\text { continues to emit } \\
\text { whereas developed } \\
\text { world has already } \\
\text { started to decline. }\end{array}$ \\
\hline $\begin{array}{l}\text { Increased } \\
\text { commitment }\end{array}$ & $\begin{array}{l}\text { Negotiation } \\
\text { after 2030 } \\
\text { leads to } \\
\text { rapid peak in } \\
\text { emissions }\end{array}$ & $\begin{array}{l}\text { Current reduction rates } \\
\text { upped by 1\% per year. } \\
\text { All peak by 2040. }\end{array}$ & $\begin{array}{l}\text { Some regions achieve } \\
\text { carbon neutrality in } \\
\text { 2075. } \\
\text { All regions emit less than } \\
\text { in 2100 than in 2009. }\end{array}$ \\
\hline $\begin{array}{l}\text { Stringent } \\
\text { commitment } \\
\text { (SC) }\end{array}$ & $\begin{array}{l}\text { Urgency of } \\
\text { early peak } \\
\text { appreciated. }\end{array}$ & $\begin{array}{l}\text { All regions peak } \\
\text { emissions by 2030. } \\
\text { Increased commitment } \\
\text { otherwise. }\end{array}$ & $\begin{array}{l}\text { All regions achieve zero } \\
\text { emission by 2100; half } \\
\text { by 2075. }\end{array}$ \\
\hline $\begin{array}{l}\text { Highly } \\
\text { increased } \\
\text { commitment } \\
\text { (HIC) }\end{array}$ & $\begin{array}{l}\text { Rapid, } \\
\text { successful } \\
\text { global effort }\end{array}$ & $\begin{array}{l}\text { 2030 emissions peak } \\
\text { matched by 2\%-per-year } \\
\text { increase in current } \\
\text { reduction rate }\end{array}$ & $\begin{array}{l}\text { All regions become zero } \\
\text { emission by 2100. EU } \\
\text { and US by 2050. }\end{array}$ \\
\hline
\end{tabular}



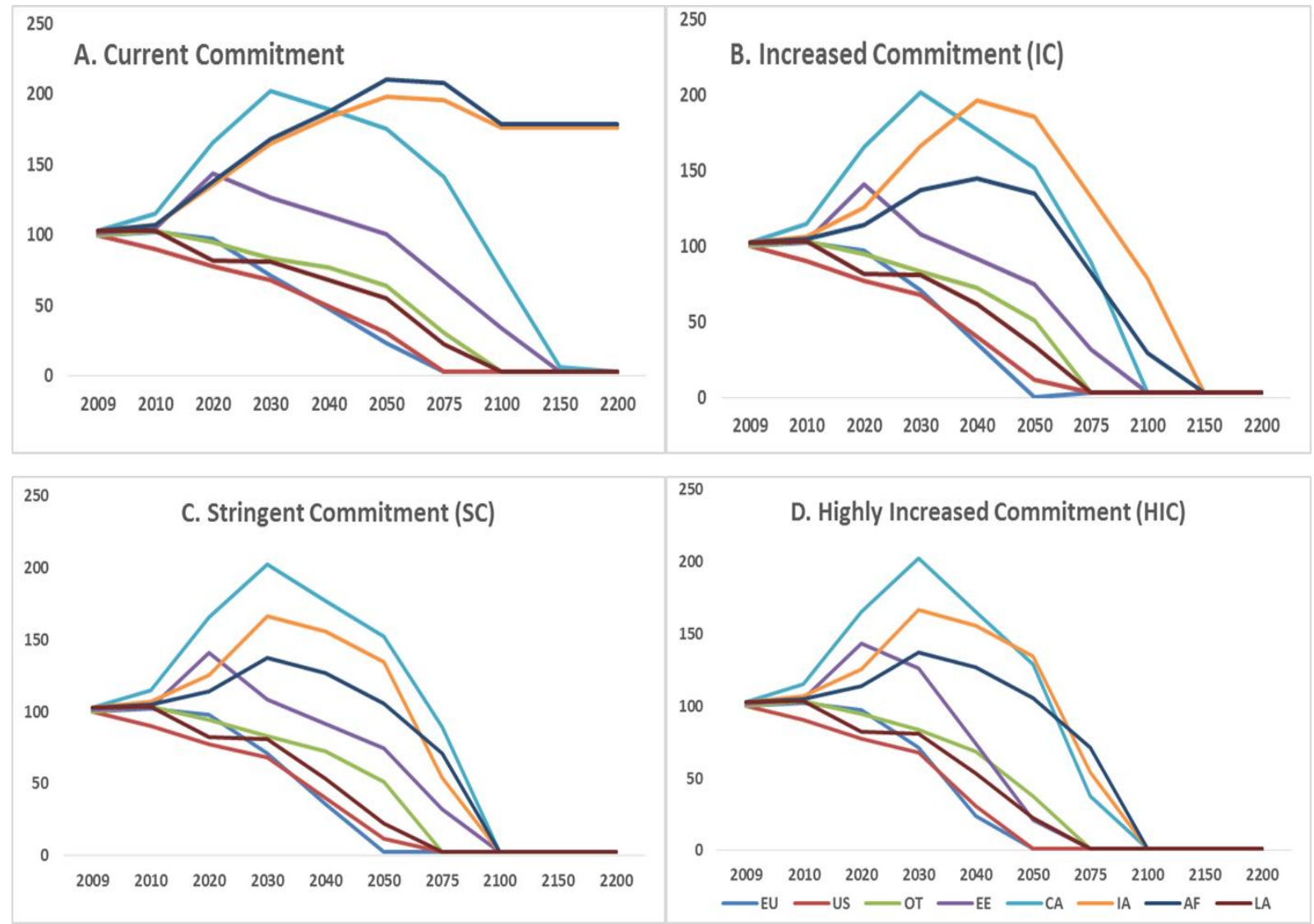

Figure 1 Emission pathways until 2200 as a percentage of current emissions; A) a continuation of the current commitments, B) Increasing the commitments post 2030 through negotiations, C) All regions peaking their emissions by 2030, D) The highest plausible commitment. The regions are European Union (EU, light blue), United States (US, pink), Other OECD countries (OT, green), Eastern Europe including former Soviet Union (EE, purple), China and central Asia (CA, cyan), India including South East Asia (IA, orange), Africa and the Middle East (AF, dark blue) and Latin America (LA, brown). Please refer text for further details of the scenarios.

\section{Climate Change Outcomes}

Carbon dioxide concentrations and radiative forcing in 2100 reduce as stronger commitments are made (Fig. 2a, b). The $\mathrm{CO}_{2}$ concentrations in both the stringent and the highly increased commitment scenarios are below $500 \mathrm{ppm}$, which is comparable to the IPCC's RCP2.6 scenario. Nonetheless none of our proposed scenarios result in a likely $(>66 \%)$ chance of warming remaining below $2{ }^{\circ} \mathrm{C}$ (Fig. 2d). Our current commitment is very unlikely $(\leq 10 \%)$ to prevent dangerous climate change (i.e. to keep global warming below $2{ }^{\circ} \mathrm{C}$ ). This analysis is consistent with previous studies (Rogelj, et al., 2016; AVOID2, 2009) which assert that the $2^{\circ} \mathrm{C}$ target is challenging. We find that even an annual emissions reduction rate of 5\%-per-year (the highest considered feasible) is insufficient to remain below $2{ }^{\circ} \mathrm{C}$, if the global emission peak year occurs in 2040 or later. 
According to our results, a plausible increase in our climate commitments (scenario IC) is sufficient to make climate change of greater than $4{ }^{\circ} \mathrm{C}$ very unlikely $(\leq 10 \%)$.

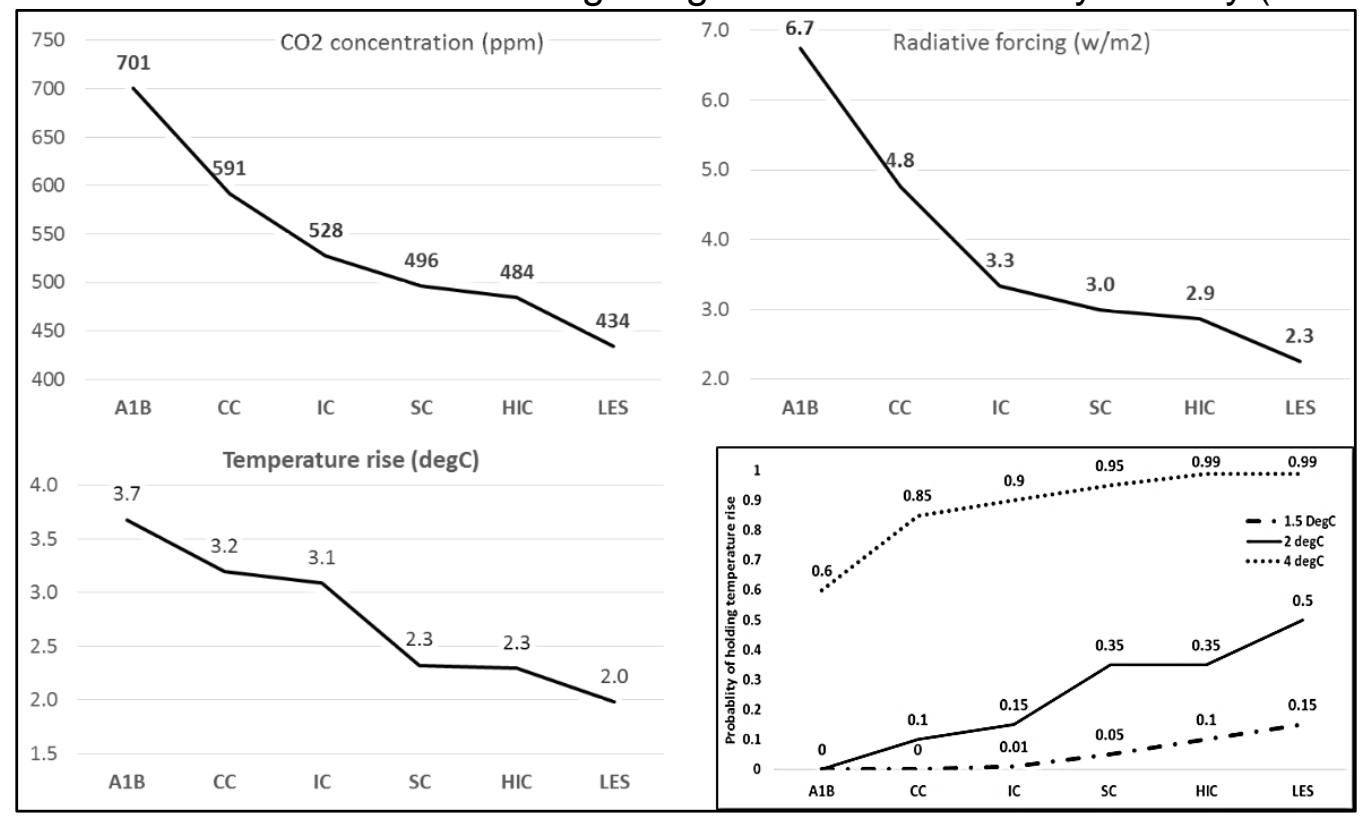

Figure 2: Climate change under different scenarios (median values for 2100). The four scenarios develop here are shown along with the A1B and the LES scenarios. A) the median $\mathrm{CO}_{2}$

concentration in ppm, B) radiative forcing in $\mathrm{W} / \mathrm{m}^{2}, \mathrm{C}$ ) global mean temperature change in ${ }^{\circ} \mathrm{C}$ and D) probability of holding below different global mean temperature thresholds

\section{Costs of NDC-based scenarios}

The costs associated with future climate arise from two different sources: "preventive costs" are associated with additional actions (or lost opportunities) aimed at lowering carbon emissions; "impacts costs" are associated with the direct consequences of climate change or the adaptation to them. The difference between these two costs compared to the A1B scenario indicate a net benefit of the policy decision (Fig. 3). 


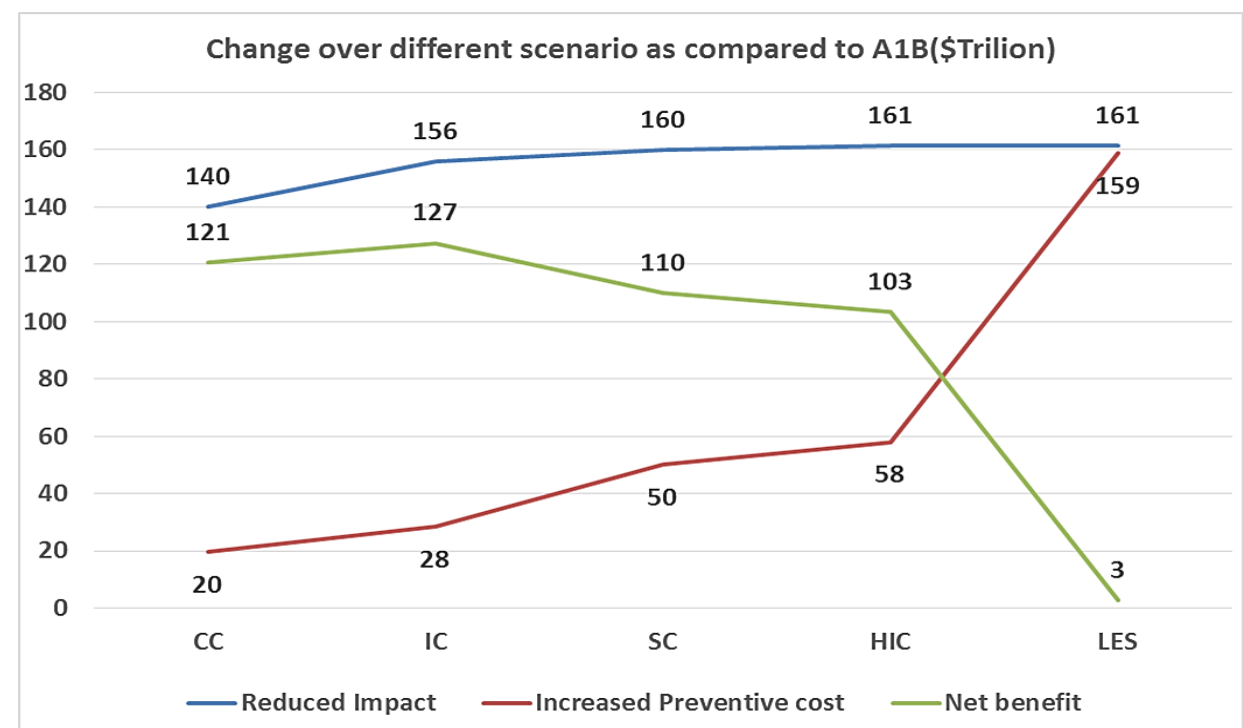

Figure 3: Costs and benefit compared to the A1B scenario. All values shown here are the median costs in 2100 . The low probability, yet high cost of climate discontinuities results in the average (mean) costs returning even greater net benefits.

All scenarios developed here have a net benefit of reduced impacts over US $\$ 100$ trillion (although the majority of this benefit occurs in the 22nd century, making climate change investment an intergenerational investment). As the climate mitigation commitments become more substantial, so do the preventive costs. The reduced impacts cost saturates for emissions reduction larger than those in the SC scenario. However, this model neither covers all climate damages nor potential co-benefits from mitigation (Bain, et al., 2016; IPCC, 2014).

Regional costs (Fig. 4) are not uniformly distributed across the globe (Goulder \& Pizer, 2006). Moving to the most ambitious scenario will result very high preventative costs for the least developed regions (Fig. 4B), despite them simultaneously suffering the highest impacts cost (Fig. 4D). This highlights the importance of equity, justice and fairness as important conditions in climate policy design. The wide probable range of impact and effect (e.g. Indian \& South East Asian preventative costs may be the largest cost or the largest savings, Fig. 4B) is associated with the uncertainty in warming (Fig. 2). Temperature rise beyond tolerable limits will trigger discontinuity and lead to catastrophic damages (Hope, 2010). Strong commitment will reduce the probability of reaching these dangerously extreme warmings (Fig. 2D). 

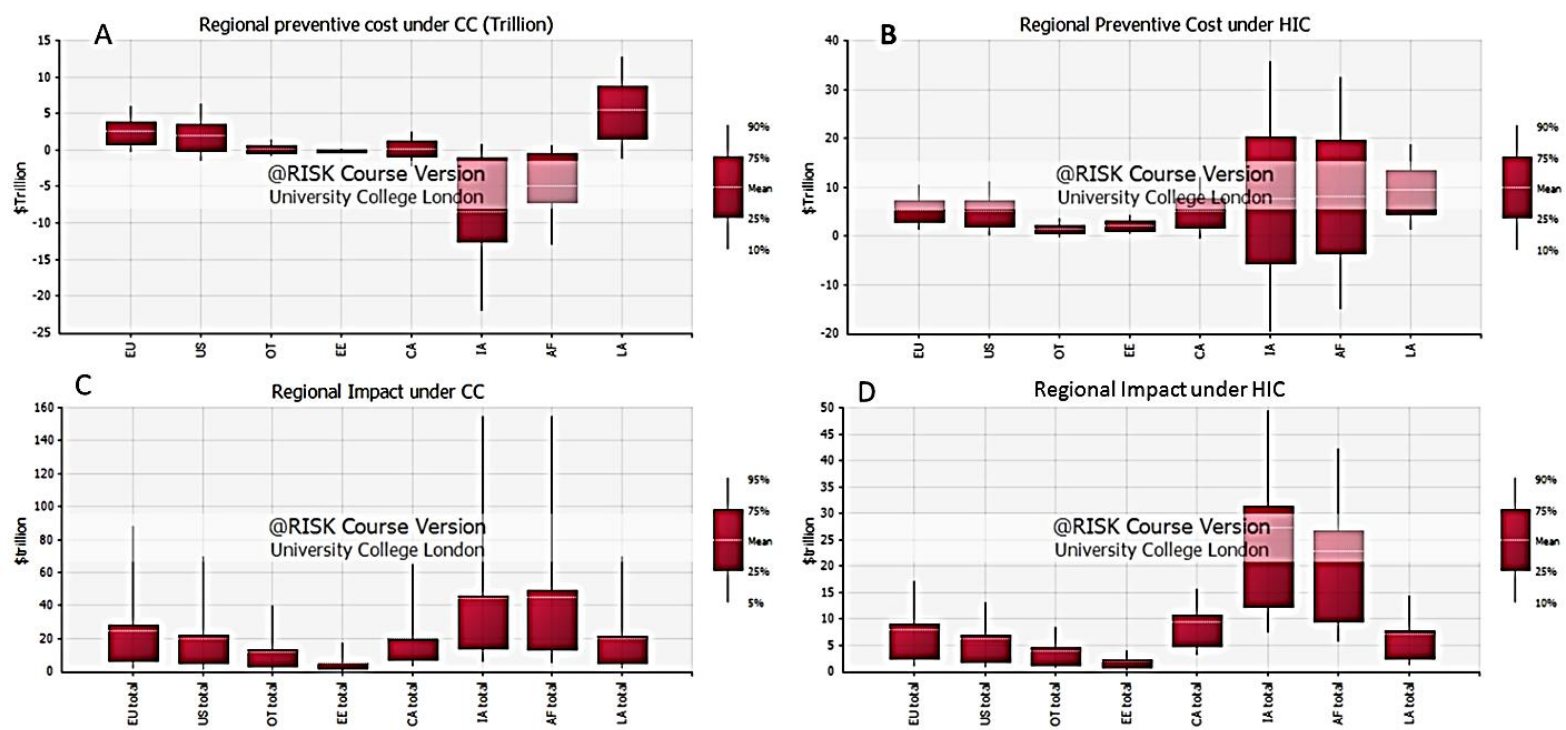

Figure 4 Preventive and impact costs for every region (at 2100). The left panels show the preventative (A) and impacts $(C)$ costs under the current commitments. The Highly Increased Commitment scenario is shown in the right panels with its regional preventive (B) and impacts costs (D).

\section{Social Cost of Carbon}

Many studies (Schellnhuber, et al., 2016b; Nordhaus, 1991; Hope, 2013; MacKay, et al., 2015) suggest carbon pricing as a solution to emission reduction. The mean social cost of carbon dioxide is calculated as the aggregate value of damage associated with an additional ton of $\mathrm{CO}_{2}$ emitted. The estimated social cost of carbon (\$103) under A1B scenario is in line with other estimates (US\$106) (Wong, et al., 2015).

The mean social cost of carbon under the current commitments (CC) is US\$74 per ton of $\mathrm{CO} 2$, only three-quarters of the cost seen under the A1B scenario. With increasing commitment, the social cost of carbon reduces. This result is consistent with a non-linear climate system that contains thresholds and discontinuities. It demonstrates that early actions reduce the damage caused by greenhouse gases and provide larger benefit in long run. Extreme damages associated with the long tail in the probability of damage costs are particularly important in determining the social cost of carbon and omitting the top 1\% values reduces the mean values significantly (Hope, 2013). For comparison present values of carbon tax are around US\$168 in Sweden, US\$68 in Switzerland (WB, 2016) whereas it is US\$16 in Denmark and Norway. The calculated social cost of carbon is substantially more than the carbon charges considered by the majority of countries (CCES, 2013) - only Sweden's US\$168 per ton is comparable. 


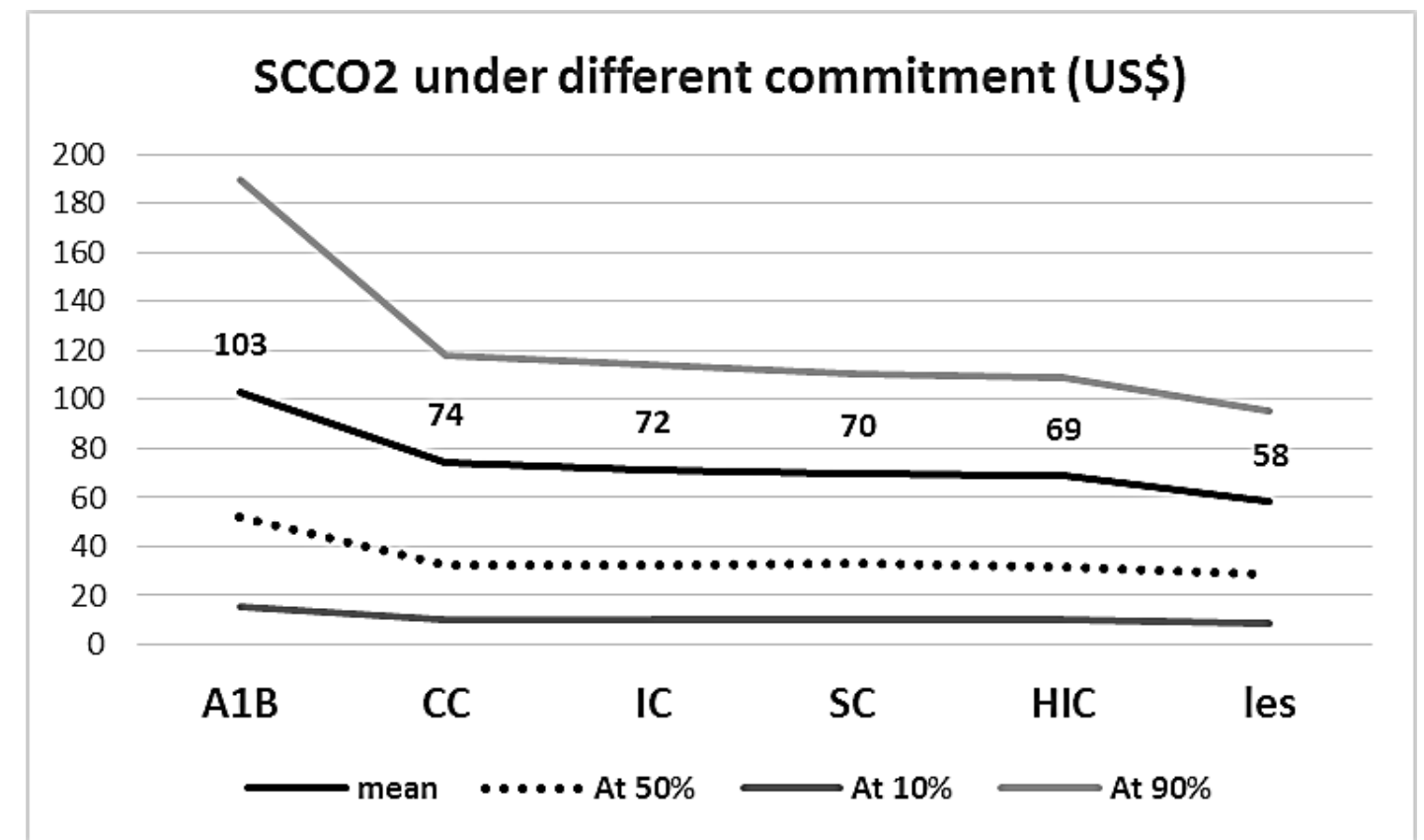

Figure 6 Social cost of carbon (US\$ per ton of CO2). We show the mean, median and 10-90\% range of estimates from the resulting probabilistic distributions.

\section{Discussion and Conclusions}

There will be a clear benefit of adopting the NDC in terms of both climate change and total economic cost. In fact, all NDC-based commitment scenarios are economically beneficial compared to the A1B baseline pathway, although not necessarily optimum. Achieving the $2{ }^{\circ} \mathrm{C}$ target clearly rests upon what follows once the current NDCs expire in 2030. We find that even when all countries peak their emissions before 2030 and subsequently achieve an annual emissions reduction rate of $5 \%$-per-year, the $2{ }^{\circ} \mathrm{C}$ target is not likely to be met (>66\%). Even though the ambitious scenarios developed here are unlikely to hit the $2{ }^{\circ} \mathrm{C}$ target, they virtually eliminate the chance of exceeding $4{ }^{\circ} \mathrm{C}$ of global warming.

As with any Integrated Assessment Model, the results of these simulations must be interpreted with caution (Wong, et al., 2015). On the one hand, to permit global simulations on such a long time scale, a large number of assumptions must be made which may underestimate the costs and impacts. On the other hand, climate mitigation policy has a wide range of social co-benefits that are accounted for in PAGE09, albeit crudely (IPCC, 2014). Consideration of these co-benefits could make climate action more palatable to politicians (Bain, et al., 2016). However the probabilistic approach taken in PAGE09 goes a long way to explore those two large uncertainties.

Our scenarios start from an assumption that all countries fulfil their national determined contribution stated commitments. If even a handful of countries fail to comply with their $\mathrm{NDC}$, then other countries may give up on the agreements. Therefore, achieving $2{ }^{\circ} \mathrm{C}$ 
requires ambitious and collaborative actions by all countries (IPCC, 2014). The scenarios here have been developed with the aim of sharing the burden fairly to achieve buy agreement from all parties. We have not included a large-scale deployment of negative emission technology into these scenarios, yet they would clearly be helpful in mitigating further climate change impacts (Bernie, et al., 2015)

\section{Bibliography}

Nordhaus, W. D., 1991. To Slow or Not to Slow: The Economics of The Greenhouse Effect. The Economic Journal, 101(407), pp. 920-937.

Andrews, T., Gregory, J. M., Webb, M. J. \& Taylor, K. E., 2012. Forcing, feedbacks and climate sensitivity in CMIP5 coupled atmosphere-ocean climate models. Geophysical Research Letters, 39(L09712), pp. 1-7.

AVOID2, 2009. Can we limit warming to $2^{\circ} \mathrm{C}$ ?. s.I.:S.n.

Bain, P. G. et al., 2016. Co-benefits of addressing climate change can motivate action around the world. Nature Climate Change, Volume 6, pp. 154-157.

Balanco, G. et al., 2014. Mitigation of Climate Change. Contribution of Working Group III to the Fifth Assessment Report of the Intergovernmental Panel on Climate Change, Cambridge, United Kingdom and New York, NY, USA: Cambridge University Press. Beck, M. \& Krueger, T., 2016. The epistemic, ethical, and political dimensions of uncertainty in integrated assessment modeling. Wiley Interdisciplinary Reviews: Climate Change, 7(5), pp. 627-645.

Bernie, D., Gohar, L. K. \& Lowe, J. A., 2015. Development of emissions pathways that lead to a range of long-term temperature, s.I.: AVOID: Avoiding dangerous climate change. Boyd, R., Cranston, T. \& Ward, B., 2015. Tracking intended nationally determined contributions: what are the implications for greenhouse gas emissions in 2030?. London, UK: ESRC Center for Climate Change Economics and Policy \& Grantham Research Institute on Climate Change and the Environment.

Boyd, R., Turner, J. C. \& Ward, B., 2015(b). Intended nationally determined contributions: what are the implications for greenhouse gas emissions in 2030?, London: ESRC Centre for Climate Change Economics and Policy \&Grantham Research Institute on Climate Change and the Environment.

Brechet, T. \& Jouvet, P.-A., 2008. Environmental innovation and the cost of pollution abatement revisited. Ecological Economics, Volume 65, pp. 262-265.

Brewer, P. R., 2012. Polarisation in the USA: Climate Change, Party Politics, and Public Opinion in the Obama Era. European Political Science, 11(1), pp. 7-17.

CAT, 2014. Climate Action Tracker. [Online]

Available at: http://climateactiontracker.org/methodology.html

[Accessed 2106 2016].

CCES, 2013. Options and Considerations for a Federal Carbon Tax. [Online]

Available at: http://www.c2es.org/publications/options-considerations-federal-carbon-tax [Accessed 2508 2016].

Dasgupta, P., 2008. Discounting climate change. J Risk Uncertain, Volume 37, p. 141169. 
Dayaratna, K. D. \& Kreutzer, D. W., 2013. Loaded DICE:An EPA Model Not Ready for the Big Game, s.l.: The Heritage Foundation.

Diaz, D., 2014. Evaluating the Key Drivers of the US Government's Social Cost of Carbon: A Model Diagnostic and Inter-Comparison Study of Climate Impacts in DICE, FUND, and PAGE. s.I.:Social Science Research Network.

EEA, 2010. EU greenhouse gas emissions: more than half way to the '20 \% target by 2020', Copenhagen, Denmark: European Environment Agency.

Ekholm, T. \& Lindroos, T. J., 2015. An analysis of countries' climate change mitigation contributions towards the Paris agreement, FI-02044 VTT, Finland: VTT Technical Research Centre of Finland Ltd.

EPA, 2015. EPA Fact Sheet: Social Cost Of Carbon, s.l.: EPA.

Fuss, S. et al., 2014. Betting on negative emissions. Nature Climate Change, Volume 4, pp. 850-853.

Ghambhir, A., Napp, T. N., Emmott, C. J. \& Anandarajah, G., 2014. India's CO2 emissions pathways to 2050: Energy system, economic and fossil fuel impacts with and without carbon permit trading. Energy, Volume 77, pp. 791-801.

Goulder, L. H. \& Pizer, A. W., 2006. The economics of climate change. Cambridge, MA 02138: National Bureau of Economic Research.

Green, F. \& Stern, N., 2015. China's "new normal":structural change, better growth, and peak emissions, London, UK: The Grantham Research Institute on Climate Change and the environment \& The Centre for Climate Change Economics and Policy.

Hope, C., 2006. The Marginal Impact of CO2 from PAGE2002: An Integrated Assessment Model Incorporating the IPCC's Five Reasons for Concern. The Integrated Assessment Journal, 6(1), p. 19-56.

Hope, C., 2010. Risk, aggregate and distribution of the impact, discontinuity and catastrophic impact of climate change. Washington DC, USA: Prepared for the Climate Damages Workshop.

Hope, C., 2011. The PAGE09 Integrated Assessment Model: A Technical Description. Cambridge, UK: Judge Business School, Cambridge University.

Hope, C., 2013. Critical issues for the calculation of the social cost of CO2: why the estimates from PAGE09 are higher than those from PAGE2002. Climatic Change, Volume 117 , p. 531-543.

Hope, C. \& Hope, M., 2013(b). The social cost of CO2 in a low-growth world. Nature Climate Change, Volume 3, pp. 722-724.

Innes, M., 2016. Mining Companies Buy Political Influence in Australia, Report Says. [Online]

Available at: http://www.lcnewsgroup.com/mining-companies-buy-political-influence-

australia-report-says/

[Accessed 1708 2016].

IPCC, 2013. Summary for Policymakers. In: Working Group I to the Fifth Assessment Report of the Intergovernmental Panel on Climate Change. Cambridge, United Kingdom and New York, NY, USA: Cambridge University Press.

IPCC, 2014. IPCC-Fifth Assessment Report- WGIII Chapter-6: Assessing Transformation Pathways, Cambridge, UK: Cambridge University Press. 
IPCC, 2014. Summary for policymakers and Technical Summary in Climate Change 2014 Mitigation of Climate Change.Contribution of Working Group III to the Fifth Assessment Report, Cambridge, UK and New York, USA: Cambridge University Press. Jacquet, J. \& Jamieson, D., 2016. Soft but significant power in the Paris Agreement. Volume 6, pp. 643-646. Janicke, M., 2008. Ecological modernisation: new perspectives. Journal of Cleaner Production, 16(5), pp. 557-565.

Kitous, A. \& Keramidas, K., 2015. Analysis of scenarios integrating the INDCs, s.l.: Joint Research Centre, The European Commission's science and knowledge service.

Korsbakken, J. I., Peters, G. P. \& Andrew, R., 2016. Uncertainties around reductions in China's coal use and CO2 emissions. Nature Climate Change, Volume 6, pp. 687-690. Kriegler, E. et al., 2015. Diagnostic indicators for integrated assessment models of climate policy. Technological Forecasting \& Social Change, Volume 90, p. 45-61.

$\mathrm{Li}, \mathrm{H}$. \& Qi, Y., 2011. Comparison of China's Carbon Emission Scenarios in 2050.

Advances in Climate Change Research, 2(4), pp. 193-202.

Mackay, D. J., Cramton, P., Ockenfels, A. \& Stoft, S., 2015. Price carbon — I will if you will. Nature, Volume 526, pp. 315-316.

Myllyvirta, L., 2015. Smoke and Mirrors: How Europe's biggest polluters became their own regulators. Brussels, Belgium: Greenpeace.

Peters, G. P., 2016. The 'best available science' to inform $1.5^{\circ} \mathrm{C}$ policy choices. Nature Climate Change, Volume 6, pp. 646-649.

Pindyck, R. S., 2013. Climate Change Policy: What Do the Models Tell Us?†. Journal of Economic Literature, 51(3), pp. 860-872.

Pindyck, R. S., 2015. The use and misuse of models for climate policy. Cambridge, Massachusetts, USA: Massachusetts Institute of Technology.

Pollitt, H., Summerton, P. \& Billington, S., 2014. An analysis of the impact of low-carbon policies on households, businesses and the macro-economy, Cambridge, UK: Cambridge Econometrics Limited.

Puiu, T., 2015. The 2 degrees goal is a political figure, not generated by scientific reports', says IPCC at COP21. Pitesti, Arges, Romania: ZME Science.

Rogeij, J. et al., 2014. Probabilistic cost estimates for climate change mitigation. Nature, Volume 493, pp. 79-83.

Rogelj, J. et al., 2016. Paris Agreement climate proposals need a boost to keep warming well below $2{ }^{\circ} \mathrm{C}$. Nature, 534(7609), pp. 631-639.

Rogelj, J. et al., 2011. Emission pathways consistent with a $2^{\circ} \mathrm{C}$ global temperature limit. Nature Climate Change, Volume 1, pp. 413-418.

Schellnhuber, H. J., Rahmstorf, S. \& Winkelmann, R., 2016b. Why the right climate target was agreed in Paris. Nature Climate Change, Volume 6, pp. 649-653.

Schleussner, C.-F.et al., 2016. Science and policy characteristics of the Paris Agreement temperature goal. Nature Climate Change, Volume Online published 25th, July, 2016.

Serchuk, D., 2009. Calculating The True Cost Of Carbon. [Online]

Available at: http://www.forbes.com/2009/06/03/cap-and-trade-intelligent-investing-

carbon.html

[Accessed 2508 2016]. 
Stern, N., 2007. The Economics of Climate Change: The Stern Review. Cambridge, UK: Cambridge University Press.

Stern, N., 2013. The Structure of Economic Modeling of the Potential Impacts of Climate Change: Grafting Gross Underestimation of Risk onto Already Narrow Science Models. Journal of Economic Literature, 51(3), p. 838-859.

Tol, R. S., 1999. Spatial and Temporal Efficiency in Climate Policy: Applications of FUND. Environmental and Resource Economics, Volume 14, pp. 33-49.

Tol, R. S., 2015. Modified Ramsey Discounting for Climate Change, s.I.: Center for Economic Studies \& Ifo Institute.

UNFCCC, 2014 (b). Kyoto Protocol. [Online]

Available at: http://unfccc.int/kyoto protocol/items/2830.php

[Accessed 2807 2016].

UNFCCC, 2015b. Adoption of the Paris Ageement, s.l.: UNFCC.

UNFCCC, 2015. Report on the structured expert dialogue on the 2013-2015 review

UNFCCC, 2015. Synthesis report on the aggregate effect of the intended nationally

determined contributions, s.l.: United Nation Framework Concention on Climate Change.

Vuuren, D. P. V. et al., 2011. RCP2.6: exploring the possibility to keep global mean

temperature increase below $2^{\circ} \mathrm{C}$. Climatic Change, Volume 109, pp. 95-116.

Wahba, M. \& Hope, C., 2006. The marginal impact of carbon dioxide under two scenarios of future emissions. Energy Policy, Volume 34, pp. 3305-3316.

Warren, R. et al., 2010. The economics and climate change impacts of various greenhouse gas emission pathways and a comparison between base line and policy emissions scenarios, s.I.: Workstream 1 Deliverable 3, Report 1 of the AVOID programme (AVMS1/D3/R01)..

Warren, R. et al., 2013. The AVOID programme's new simulations of the global benefits of stringent climate change mitigation. Climatic Change, Volume 120, pp. 55-70.

WB, 2016. Putting a Price on Carbon with a Tax. [Online]

Available at:

http://www.worldbank.org/content/dam/Worldbank/document/Climate/background-

note carbon-tax.pdf

[Accessed 2508 2016].

Whiteman, G., Hope, C. \& Wadhams, P., n.d. Climate science: Vast costs of Arctic change. Nature, Volume 499, pp. 401-403.

Wilkerson, J. T., Leibowicz, B. D., Turner, D. D. \& Weyant, J. P., 2015. Comparison of integrated assessment models: Carbon price impacts on U.S.energy. Energy Policy, Volume 76, p. 18-31.

Wong, K. Y., Chuah, J. H. \& Hope, C., 2015. The impact of time horizon on integrated climate assessment models. Clean Techn Environ Policy, Volume 17, pp. 2361-2374. Zahran, S., Kim, E., Chen, X. \& Lubell, M., 2007. Ecological Development and Global Climate Change: A Cross-National Study of Kyoto Protocol Ratification. Society and Natural Resources, Volume 20, pp. 37-55. 